
\title{
28 Research Square \\ Palladium-catalyzed selective oxidative amination of olefins with Lewis basic amines
}

\section{Yangbin Jin}

South China University of Technology

\section{Chunsheng Li}

South China University of Technology

Meng Li

South China University of Technolog

\section{Wanqing Wu}

South China University of Technology https://orcid.org/0000-0001-5151-7788

Huanfeng Jiang ( $\nabla_{\text {jianghf@scut.edu.cn ) }}$

South China University of Technology https://orcid.org/0000-0002-4355-0294

\section{Article}

Keywords: amines, sustainability, green chemistry, organic molecules, functional materials

Posted Date: July 22nd, 2021

DOl: https://doi.org/10.21203/rs.3.rs-623757/v1

License: (c) (1) This work is licensed under a Creative Commons Attribution 4.0 International License. Read Full License

Version of Record: A version of this preprint was published at Nature Chemistry on September 1st, 2022. See the published version at https://doi.org/10.1038/s41557-022-01023-x. 


\section{Abstract}

Amines are prominent in natural products, pharmaceutical agents, and agrochemicals. Moreover, they are synthetically valuable building blocks for the construction of complex organic molecules and functional materials. However, amines, especially aliphatic and aromatic amines with free $\mathrm{N}-\mathrm{H}$, are prone to coordinate with transition-metal and deactivating the catalyst, posing a tremendous challenge to the application of Lewis basic amines in the amination of olefins. Herein we present the first case of oxidative amination of simple olefins with various Lewis basic amines. The combination of a palladium catalyst, 2,6-dimethyl-1,4-benzoquinone (2,6-DMBQ), and a phosphorous ligand leads to the efficient synthesis of alkyl and aryl allylamines. A series of allylamines are obtained with good yields and excellent regio- and stereoselectivities. Intramolecular amination to synthesize tetrahydropyrrole and piperidine derivatives was also realized. Mechanistic investigations reveal that the reaction undergoes allylic $\mathrm{C}\left(\mathrm{sp}^{3}\right)-\mathrm{H}$ activation and subsequent functionalization.

\section{Introduction}

The physiological properties of amines and their antibacterial and anticancer activities have rendered them highly efficient pharmaceutical agents ${ }^{1,2}$. Approximately $80 \%$ of the top 200 small molecule pharmaceuticals by retail sales in 2018 contain an amine moiety. The allylamine derivatives are an outstanding regimentation of prescription medicines ${ }^{3}$, including afatinib, pentazocine and naftifine etc. (Fig. 1A). Naftifine is one of the most representative commercial antifungal drugs, which exhibits biological activities against extensive pathogenic fungi both in vivo and in vitro ${ }^{4}$. Remarkably, the tertiary allylamine functional group appears to be responsible for the activity against fungi. In the traditional approaches for the synthesis of linear allylic amines, allylic alcohol was regarded as a leaving group prior to being substituted by the nitrogen group and was extremely requisite ${ }^{5,6}$. Current strategies also require a multistep approach and usually demand one reactant to be activated before the construction of a C-N bond $^{7,8}$.

Palladium-catalyzed oxidative amination of olefins is an atom-economical pathway to construct ubiquitous C-N bonds ${ }^{9-13}$ (Fig. 1B). Despite the simplicity and high efficiency of this reaction, there are some factors that have hindered the development of a comprehensive strategy for the oxidative amination of simple olefins and Lewis basic amines. Aliphatic and aromatic amines with free $\mathrm{N}-\mathrm{H}$ often coordinate to palladium salts more strongly than olefins, leading to the formation of bis(amine)palladium complex ${ }^{14,15}$, thus remarkably declining the electrophilicity of palladium and decreasing the reactivity of the catalyst (Fig. 1C, upper). Whereas, several protocols have been successfully utilized to avoid the inactivation of the palladium catalyst. The primary approach is the employment of non-basic nitrogen nucleophiles to reduce the electron density of amines, which could undergo efficient oxidative coupling with alkenes ${ }^{16-20}$. Remarkably, the coordination of amine and palladium salts can be dramatically avoided by increasing the steric hindrance around the $\mathrm{N}-\mathrm{H}$ bond ${ }^{21,22}$. Besides, our group discovered that the addition of halide ion salts could be a practical approach through promoting the 
dissociation of the nitrogen-palladium complex to reinstate the reactivity of the catalyst ${ }^{23}$. Moreover, we recently reported an application of electron-rich olefins with aromatic amines for the synthesis of $\alpha$-amino acid esters, which reveals that reinforcing the electron density of alkenes could also be workable ${ }^{24}$. The electrostatic repulsion between the olefin $\pi$-system and the nitrogen lone pair, as well as the Markovnikov and anti-Markovnikov selectivity, also generate a huge challenge to the amination of olefins. Although significant breakthroughs have been evoked in recent years, the feasible palladium-catalyzed oxidative amination of olefins with aliphatic amines has not been realized yet.

In our efforts to actualize a direct oxidative amination of simple olefins with aliphatic and aromatic amines, we proposed an unconventional catalytic system to avoid the deactivation of the palladium catalyst poisoned by Lewis basic amines or polymerizing to palladium black (Fig. 1C, lower). Firstly, the utilization of reductive phosphine ligands accelerated the classic $\mathrm{C}-\mathrm{H}$ bond activation and increased the electrophilicity of $\pi$-allylpalladium complexes ${ }^{25}$. On the other hand, the oxidative quinone oxidants achieved the rapid subsequent $\mathrm{C}-\mathrm{N}$ bond construction and acted as an electron transfer reagent for $\mathrm{Pd}(0) / \mathrm{Pd}(\mathrm{II})$ reoxidation ${ }^{26,27}$. Therefore, such a unique method could preserve the high catalytic activity of the $\mathrm{Pd}$ catalyst by stabilizing the $\mathrm{Pd}(\mathrm{II}) / \mathrm{Pd}(0) / \mathrm{Pd}(\mathrm{II})$ catalytic cycle. Here we report palladium-catalyzed selective oxidative amination of readily available olefins with dialkyl and aromatic amines via $\mathrm{C}\left(\mathrm{sp}^{3}\right)-\mathrm{H}$ activation to build architecturally versatile and functionally diverse allylamines in a single step. This protocol exhibits broad functional-group tolerance and enriches the synthetic route of amine drugs, such as naftifine and flunarizine, providing a straightforward approach to late-stage functionalization of complex natural products and chemical drugs. Under modified reaction conditions, the intramolecular amination reactions of $N$-(hex-5-en-1-yl)anilines and $N$-(hept-6-en-1-yl)anilines were also realized, delivering the expected tetrahydropyrrole and piperidine derivatives with satisfactory yields and excellent regioselectivities.

\section{Results}

Optimization of the reaction conditions. Our initial exploration focused on accomplishing the selective oxidative amination of allylbenzene with dipropyl-amine (see Tables S1 to S4 for more details). When employing $\mathrm{Pd}(\mathrm{OAc})_{2}$ as a catalyst, $\mathrm{BQ}$ as oxidant, $\mathrm{PPh}_{3}$ as ligand and toluene as solvent, the expected amination product was afforded in $60 \%$ yield. The blank control experiments indicated that the combination of phosphine ligands and oxidative quinone oxidants dominated this novel amination process. Considering the indispensable effect of phosphine ligands and quinone oxidants, the optimal association of ligands and oxidants was inspected cautiously, as shown in Tables S3. Several quinone oxidants including BQ, 2,6-DMBQ etc. were combined with different mono-dentate and bidentate phosphine ligands. The results revealed that the combination of 2,6-DMBQ and DPPE achieved the effective construction of allylamines in $90 \%$ yield. We suspected that in the air, the phosphorus ligands would be slowly oxidized, and at the same time, some of the olefins will be isomerized into internal olefins. The examination of atmosphere and the loading of catalyst and ligand suggested that the combination of $5 \mathrm{~mol} \% \mathrm{Pd}(\mathrm{OAc})_{2}$ and 10 mol\% DPPP was the optimal choice under $\mathrm{N}_{2}$ atmosphere, 
allowing the exclusive formation of $\mathbf{3}$ in $94 \%$ yield, and the olefin usage could be reduced to 1.2 equivalents.

Substrate scope of aliphatic amines and olefines. Under the optimized conditions, a wide range of aliphatic amines were then investigated for amination with allylbenzene (Fig. 2). Various alkyl chain amines could be converted into the corresponding products in 70\%-94\% yields and excellent stereoselectivities (3-10). Substrates with functional group (cyano and hydroxyl) appending to the alkyl chain were well accommodated under the mild conditions, giving the desired 3-

(cinnamyl(methyl)amino)propanenitrile (7) and $\boldsymbol{\delta}$-hydroxylamine derivative (8). To our delight, amino alcohols and amino acid esters could also be compatible with this type of reaction, converting to the target products (11-14) in 59\%-72\% yields with excellent regio- and stereoselectivities. Next, a variety of readily available cyclic amines, such as hexamethyleneimine, 3-pyrroline and substituted piperidines also underwent the amination and transformed to the corresponding products (15-24) in moderate to good yields. Nortropinone and (1S,4S)-2-Boc-2,5-diazabicyclo [2.2.1] heptane with bridged skeleton proceeded the amination process efficiently to afford the corresponding allylic amines ( 22 and $\mathbf{2 3}$ ) in $59 \%$ and $89 \%$ yields, respectively. Notably, when 3-pyrroline was employed in the reaction, the aromatization product 1cinnamyl-1 $H$-pyrrole (24) was obtained in $75 \%$ yield. Fused heterocyclic amine, morpholine, thiomorpholine and different substituted piperazines were also tolerated in this reaction system, delivering the expected products (25-31) in 43\%-85\% yields. For the substrates containing multiple $\mathrm{N}-\mathrm{H}$ sites, the amination exclusively occurred on the less steric hindrance and more electron-rich site. For example, evaluation of decahydroisoquinoline derivative bearing two $\mathrm{N}-\mathrm{H}$ sites $\left(\mathrm{N}^{1}\right.$ and $\left.\mathrm{N}^{4}\right)$ indicated that preferential amination at the $\mathrm{N}^{1}$ site over the $\mathrm{N}^{4}$ site, probably due to the stronger nucleophilicity of $\mathrm{N}^{1}$ and the larger steric hindrance of $\mathrm{N}^{4}$ (32, 86\% yield). Moreover, various $\mathrm{N}$-substituted benzylamine substrates could also convert to the cross-coupling products in good yields (55 to 92\%) with excellent stereoselectivities (33-43).

In addition to the great applicability of aliphatic amine substrates, a variety of simple olefins were compatible with this process (Fig. 2). Various substituted allylbenzenes were tolerated, delivering high yields and sole stereoselectivities (44-58). Substituents at the ortho-, meta-, or para-positions on the allylbenzenes could be accommodated. The effect of steric hindrance on the reaction was almost negligible. It was noteworthy that substituting the phenyl ring with electron-withdrawing groups generally led to higher yields and efficiency comparing with electron-rich substrates. For instance, $95 \%$ yield of the product could be obtained for $p-\mathrm{CF}_{3}$ substituted allylbenzene, whereas the allylbenzene (49) with a $p$ $\mathrm{OCH}_{3}$ substituent was formed only in $84 \%$ yield. Moreover, heterocyclic olefin was also suitable for the reaction and the desired allylic amine (59) was formed in $83 \%$ yield. When slightly adjusting the reaction conditions, the feedstock alkene, such as 1-octene and several functionalized alkenes could participate well in this oxidative amination, generating the corresponding products $(60-65)$.

Synthetic applications. Considering the widespread presence of alkylamines in small molecular drugs and natural products, the efficient synthesis and late-stage functionalization of such compounds could 
indeed manifest the utility of this oxidative amination. Under the standard conditions, a series of pharmaceutical agents and bioactive molecules, such as cytisine, amoxapine (CCDC 2038362), desloratadine, dehydroabietylamine, sitagliptin, atomoxetine, desipramine, estrone, (+)-allylated- $\boldsymbol{\sigma}$ tocopherol underwent the oxidative amination effectively to afford the corresponding allylamine derivatives (66-75) in satisfactory yields (35 to 79\%) with excellent regio- and stereoselectivities (Fig. 3A). Moreover, the synthesis of bioactive molecules was also feasible. Notably, the product 76 naftifine ${ }^{28}$, a commercially available antifungal drug, could be obtained directly from the amination of allylbenzene and 1-methyl-aminomethyl naphthalene in one single step in 85\% yield (Fig. 3B). Cinnarizine (77) and flunarizine (6) (78) were accessed in a two-step sequence proceeding in $92 \%$ and $86 \%$ yields, respectively (Fig. 3C). The product 79, which was formulated from benzyl-protected tryptamine and allylbenzene via this oxidative amination reaction, was an AC1 inhibitor ${ }^{29}$ (Adenylyl cyclase type I (AC1) belongs to the family of adenylyl cyclases, which are associated with neuropathic and inflammatory pain) (Fig. 3D). Additionally, abamine SG derivatives ${ }^{30} \mathbf{8 0}$, an effective inhibitor in the biosynthesis of abscisic acid, was assembled in $79 \%$ yield with two steps (Fig. $3 \mathrm{E}$ ).

Substrate scope of aromatic amines and olefines. We next investigated extension of the Pd-catalyzed oxidative amination of olefins with aromatic amines (Fig. 4). The basicity and affinity of aromatic amines are comparatively weaker than those of aliphatic ones, leading to a decrease in their coordination to transition-metal. The employ of monodentate phosphorus ligand could maintain the activity of the catalyst, and $\mathrm{O}_{2}$ could be used as the terminal oxidant to complete the catalytic cycle. The substrate applicability of primary anilines for intermolecular amination was first investigated. Both halogen and electron-donating-substituted anilines can achieve moderate to high yields ( $50 \%$ to $81 \%$ ). Substituents at either ortho-, meta-, or para-position on the anilines could be accommodated, and higher yields were obtained with large steric hindrance on anilines. The range of different types of nitrogen substituted anilines for intermolecular amination was subsequently probed (94 to 101). Notably, the 3anilinopropionitrile was also suitable for the reaction to give the desired product $\mathbf{9 8}$, which could proceed downstream synthetic manipulation. Various substituted allylbenzenes were tolerated in this transformation, and the corresponding products were obtained in 70 to $85 \%$ yields with sole stereoselectivities. Skipped dienes, 2-methyl-3-phenyl-1-propene, and heterocyclic olefins were also well tolerated in this transformation, and the desired allylic amines $(108,113$, and 114$)$ were obtained in moderate to high yields. Moreover, the reactions of unactivated simple aliphatic alkenes afforded the desired products in synthetically useful yields. Under modified reaction conditions, the scope of the intramolecular amination was then evaluated. The substrate 118 bearing various electron-rich or electrondeficient functionalities on the aryl ring underwent the reaction effectively to afford the corresponding tetrahydropyrrole and piperidine derivatives (119 to 130) in 35-98\% yields with excellent regioselectivities.

Mechanistic investigations. To gain more insight into the palladium-catalyzed oxidative amination of olefins, kinetic analysis experiments for allylbenzene were conducted under optimal reaction conditions. The rate data indicated a first-order dependence on the concentration of Pd catalyst, DPPP and allylbenzene (Fig. 5A), which revealed that the formation of $\pi$-allylpalladium complex through the $\mathrm{C}-\mathrm{H}$ 
activation of olefins should be the rate-determining step. However, dipropylamine, which could easily coordinate with the palladium catalyst and suppressed the formation of $\pi$-allylpalladium complex, indicated a zero-order in this reaction. This result suggested that the coordination of DPPP with the palladium catalyst was much stronger than dipropylamine, and the toxic effect of amine could be ignored. Inter- and intramolecular competitive kinetic isotopic effect (KIE) studies were also explored (Fig. $5 \mathrm{~B})$. The results exhibited a high $\mathrm{KIE}\left(k_{\mathrm{H}} / k_{\mathrm{D}}\right)$ value of 4.6 and 2.8 for inter- and intramolecular competitions respectively, implying that the allylic $\mathrm{C}$-H cleavage contributes to the rate-determining step. A preliminary Hammett study was performed to investigate the electronic effect on substituents appended to the olefines (Fig. 5C). A $\rho$ value of 0.5355 was obtained for a series of substituted allylbenzenes, indicating that electron-withdrawing groups produced an increase in the amination reaction rate. This is consistent with the mechanism of $\mathrm{C}-\mathrm{H}$ activation, and the electron-poor olefins could promote the ligand exchange with the palladium complex ${ }^{31}$. Alternatively, the electron-withdrawing substituents would increase the activity of the allylpalladium intermediate, accelerating subsequent functionalization.

Combining the aforementioned kinetics and Hammett experiments, a proposed catalytic cycle was shown in Fig. 5D. The combination of phosphorus ligands and palladium catalyst is the key to avoid the catalyst being poisoned by Lewis basic amines, after the highly active allyl-palladium intermediate was generated via $\mathrm{C}-\mathrm{H}$ activation, amines underwent a nucleophilic attack on the allyl position, leading to the target product. It is worth noting that when the nucleophile was aromatic amines, $\mathrm{Pd}(0)$ could be oxidized to $\mathrm{Pd}(\mathrm{II})$ by oxygen as the terminal oxidant, generating $\mathrm{H}_{2} \mathrm{O}$ as the sole side-product.

\section{Conclusion}

In summary, this unconventional counterbalance catalytic system enables the coupling of a series of Lewis basic amines and olefins to afford corresponding alkyl and aryl allylamines. We anticipate that this approach will address a long-standing unsolved problem posed by oxidative amination chemistry and will greatly facilitate the post-modification of exiting chemical drugs and the discovery of new small molecular pharmaceuticals.

\section{Methods}

General procedure A for the synthesis of allylamines 3 to 59,66 to 75 . In a $25 \mathrm{~mL}$ sealed test tube charged with nitrogen, a mixture of olefins $(0.24 \mathrm{mmol})$, amines $(0.2 \mathrm{mmol}), \mathrm{Pd}(\mathrm{OAc})_{2}(5 \mathrm{~mol} \%), 2,6-$ DMBQ (1.5 equiv), DPPP (10 mol \%) and $2 \mathrm{~mL}$ of toluene were vigorously stirred together at $70{ }^{\circ} \mathrm{C}$ for 24 h. After completion of the reaction and quenched by saturated brines, the mixture was extracted with ethyl acetate $(3 \times 10 \mathrm{~mL})$. The combined ethyl acetate layer was then dried over anhydrous sodium sulfate and concentrated in vacuum. Further purification by flash column chromatography on silica gel (eluting with petroleum ether/ethyl acetate) afforded the pure products. 
General procedure B for the synthesis of allylamines 60 to 65 . In a $25 \mathrm{~mL}$ sealed test tube charged with nitrogen, a mixture of olefin $(0.6 \mathrm{mmol})$, amine $(0.2 \mathrm{mmol}), \mathrm{Pd}(\mathrm{dba})_{2}(5 \mathrm{~mol} \%), 2,6-\mathrm{DMBQ}$ (1.5 equiv), DPPP ( $10 \mathrm{~mol} \%$ ) and $2 \mathrm{~mL}$ of MTBE were vigorously stirred together at $70{ }^{\circ} \mathrm{C}$ for $24 \mathrm{~h}$. After completion of the reaction and quenched by saturated brines, the mixture was extracted with ethyl acetate $(3 \times 10$ $\mathrm{mL}$ ). The combined ethyl acetate layer was then dried over anhydrous sodium sulfate and concentrated in vacuum. Further purification by flash column chromatography on silica gel (eluting with petroleum ether/ethyl acetate) afforded the pure products.

General procedure $\mathbf{C}$ for the synthesis of allylamines 81 to 114. In a $25 \mathrm{~mL}$ sealed test tube charged with 1 atm $\mathrm{O}_{2}$, a mixture of olefin $(0.4 \mathrm{mmol})$, amine $(0.2 \mathrm{mmol}), \mathrm{Pd}(\mathrm{OAc})_{2}(10 \mathrm{~mol} \%), 2,6-\mathrm{DMBQ}(20 \mathrm{~mol} \%)$, $\mathrm{PPh}_{3}(20 \mathrm{~mol} \%)$ and $2 \mathrm{~mL}$ of DMSO were vigorously stirred together at $55^{\circ} \mathrm{C}$ for $24 \mathrm{~h}$. After completion of the reaction and quenched by saturated brines, the mixture was extracted with ethyl acetate $(3 \times 10$ $\mathrm{mL}$ ). The combined ethyl acetate layer was then dried over anhydrous sodium sulfate and concentrated in vacuum. Further purification by flash column chromatography on silica gel (eluting with petroleum ether/ethyl acetate) afforded the pure products.

General procedure $D$ for the synthesis of allylamines 115 to 117 . In a $25 \mathrm{~mL}$ sealed test tube charged with $1 \mathrm{~atm} \mathrm{O}_{2}$, a mixture of olefin $(0.4 \mathrm{mmol})$, amine $(0.2 \mathrm{mmol}), \mathrm{Pd}(\mathrm{OAc})_{2}(10 \mathrm{~mol} \%), 2,6-\mathrm{DMBQ}(20 \mathrm{~mol} \%)$, $\mathrm{PPh}_{3}(20 \mathrm{~mol} \%)$ and $2 \mathrm{~mL}$ of anhydrous DMSO/DMA $=1: 1$ were vigorously stirred together at $55^{\circ} \mathrm{C}$ for $24 \mathrm{~h}$. After completion of the reaction and quenched by saturated brines, the mixture was extracted with ethyl acetate $(3 \times 10 \mathrm{~mL})$. The combined ethyl acetate layer was then dried over anhydrous sodium sulfate and concentrated in vacuum. Further purification by flash column chromatography on silica gel (eluting with petroleum ether/ethyl acetate) afforded the pure products.

General procedure $E$ for the synthesis of tetrahydropyrrole and piperidine derivatives 119 to 130 . In a 25 $\mathrm{mL}$ sealed test tube charged with nitrogen, a mixture of amine $(0.2 \mathrm{mmol}), \mathrm{Pd}(\mathrm{dba})_{2}(5 \mathrm{~mol} \%), 2,6-\mathrm{DMBQ}$ (1.5 equiv), DPPP ( $10 \mathrm{~mol} \%$ ) and $2 \mathrm{~mL}$ of MTBE were vigorously stirred together at $70^{\circ} \mathrm{C}$ for $24 \mathrm{~h}$. After completion of the reaction and quenched by saturated brines, the mixture was extracted with ethyl acetate $(3 \times 10 \mathrm{~mL})$. The combined ethyl acetate layer was then dried over anhydrous sodium sulfate and concentrated in vacuum. Further purification by flash column chromatography on silica gel (eluting with petroleum ether/ethyl acetate) afforded the pure products.

\section{Declarations}

\section{Data availability}

Crystallographic data are available free of charge from the Cambridge Crystallographic Database Centre (CCDC) under CCDC 2038362 (for 67). All other characterization data are in the supplementary materials.

\section{Acknowledgments}


The authors thank the Ministry of Science and Technology of the People's Republic of China (2016YFA0602900), the National Nature Science Foundation of China (21871095), and the Fundamental Research Funds for the Central Universities (2020ZYGXZR094) for financial support.

\section{Author contributions}

The project was conceived of and supervised by H.J.; Y.J. developed the Palladium-catalyzed selective oxidative amination of olefins with Lewis basic amines; C.L. contributed to expanding the scope for aromatic amines; M.L.and Y.J. performed the reaction mechanism studies; W.W. wrote the manuscript and incorporated revisions suggested by all authors

\section{Competing interests}

The authors declare that they have no competing interests.

\section{Additional information}

Supplementary information is available for this paper at

Correspondence and requests for materials should be addressed to H.J.

Reprints and permissions information is available at www.nature.com/reprints

\section{References}

1. Vitaku, E., Smith, D. T. \& Njardarson, J. T. Analysis of the structural diversity, substitution patterns, and frequency of nitrogen heterocycles among U.S. FDA approved pharmaceuticals. J. Med. Chem. 57, 10257-10274 (2014).

2. Mayol-Llinàs, J., Nelson, A., Farnaby, W. \& Ayscough, A. Assessing molecular scaffolds for CNS drug discovery. Drug Discov. Today. 22, 965-969 (2017).

3. Stütz, A. \& Petranyi, G. Synthesis and antifungal activity of (E)-N-(6,6-dimethyl-2-hepten-4-ynyl)-Nmethyl-1-naphthalenemethanamine (SF 86-327) and related allylamine derivatives with enhanced oral activity. J. Med. Chem. 27, 1539-1543 (1984).

4. Stütz, A., Georgopoulos, A., Granitzer, W., Petranyi, G. \& Berney, D. Synthesis and structure-activity relationships of naftifine-related allylamine antimycotics. J. Med. Chem. 29, 112-125 (1986).

5. Johannsen, M. \& Jørgensen, K. A. Allylic amination. Chem. Rev. 98, 1689-1708 (1998).

6. Sweeney, J. B., Ball, A. K., Lawrence, P. A., Sinclair, M. C. \& Smith, L. J. A Simple, broad-scope nickel(0) precatalyst system for the direct amination of allyl Alcohols. Angew. Chem. Int. Ed. 57, 10202-10206 (2018).

7. Cheng, Q., Chen, J.-T., Lin, S.-Y. \& Ritter, T. Allylic amination of alkenes with iminothianthrenes to afford alkyl allylamines. J. Am. Chem. Soc. 142, 17287-17293 (2020). 
8. Xie, Y.-J., Hu, J.-H., Wang, Y.-Y., Xia, C.-G. \& Huang, H.-M. Palladium-catalyzed vinylation of aminals with simple alkenes: A new strategy to construct allylamines. J. Am. Chem. Soc. 134, 20613-20616 (2012).

9. Wang, P.-S., Shen, M.-L., Wang, T.-C., Lin, H.-C. \& Gong, L.-Z. Access to chiral hydropyrimidines through palladium-catalyzed asymmetric allylic C-H amination. Angew. Chem. Int. Ed. 56, 16032-16036 (2017).

10. Vemula, S. R., Kumar, D. \& Cook, G. R. Palladium-catalyzed allylic amidation with N-Heterocycles via sp $^{3}$ C-H oxidation. ACS Catal. 6, 5295-5301 (2016).

11. Reed, S. A. \& White, M. C. Catalytic intermolecular linear allylic C-H amination via heterobimetallic catalysis. J. Am. Chem. Soc. 130, 3316-3318 (2008).

12. Timokhin, V. I., Anastasi, N. R. \& Stahl, S. S. Dioxygen-coupled oxidative amination of styrene. J. Am. Chem. Soc. 125, 12996-12997 (2003).

13. McDonald, R. I., Liu, G.-S. \& Stahl, S. S. Palladium(II)-catalyzed alkene functionalization via nucleopalladation: Stereochemical pathways and enantioselective catalytic applications. Chem. Rev. 111, 2981-3019 (2011).

14. Willcox, D. B., Chappell, G. N., Hogg, K. F., Calleja, J., Smalley, A. P. \& Gaunt, M. J. A general catalytic $\beta-$ C-H carbonylation of aliphatic amines to $\beta$-lactams. Science 354, 851-857 (2016).

15. Åkermark, B., Bäckvall, J. E., Hegedus, L. S., Zetterberg, K., Siirala-Hansén, K. \& Sjöberg, K. Palladiumpromoted addition of amines to isolated double bonds J. Organomet. Chem. 72, 127-133 (1974).

16. Timokhin, V. I., Anastasi, N. R. \& Stahl, S. S. Dioxygen-coupled oxidative amination of styrene. J. Am. Chem. Soc. 125, 12996-12997 (2003).

17. Brice, J. L., Harang, J. E., Timokhin, V. I., Anastasi, N. R. \& Stahl, S. S. Aerobic oxidative amination of unactivated alkenes catalyzed by palladium. J. Am. Chem. Soc. 127, 2868-2869 (2005).

18. Yin, G.-Y., Wu, Y.-C. \& Liu, G.-S. Scope and mechanism of allylic C-H amination of terminal alkenes by the palladium/PhI(OPiv) 2 catalyst system: Insights into the effect of naphthoquinone. J. Am. Chem. Soc. 132, 11978-11987 (2010).

19. Kohler, D. G., Gockel, S. N., Kennemur, J. L., Waller, P. J. \& Hull, K. L. Palladium-catalysed antiMarkovnikov selective oxidative amination. Nat. Chem. 10, 333-340 (2018).

20. Ma, R. \& White, M. C. C-H to C-N cross-coupling of sulfonamides with olefins. J. Am. Chem. Soc. $140,3202-3205$ (2018).

21. McNally, A., Haffemayer, B., Collins, B. S. L. \& Gaunt, M. J. Palladium-catalysed C-H activation of aliphatic amines to give strained nitrogen heterocycles. Nature 510, 129-133 (2014).

22. Calleja, J., Pla, D., Gorman, T. W., Domingo, V., Haffemayer, B. \& Gaunt, M. J. A steric tethering approach enables palladium-catalysed $\mathrm{C}-\mathrm{H}$ activation of primary amino alcohols. Nat. Chem. 7, 1009-1016 (2015).

23. Ji, X.-C, Huang, H.-W, Wu, W.-Q. \& Jiang, H.-F. Palladium-catalyzed intermolecular dehydrogenative aminohalogenation of alkenes under molecular oxygen: An approach to brominated enamines. J. 
Am. Chem. Soc. 135, 5286-5289 (2013).

24. Ouyang, L., Li, J.-X., Zheng, J., Huang, J.-Z., Qi, C.-R., Wu, W.-Q. \& Jiang, H.-F. Access to a-amino acid esters through palladium-catalyzed oxidative amination of vinyl ethers with hydrogen peroxide as the oxidant and oxygen source. Angew. Chem. Int. Ed. 56, 15926-15930 (2017).

25. Trost, B. M., Weber, L., Strege, P. E., Fullerton, T. J. \& Dietsche, T. J. Allylic alkylation: nucleophilic attack on .pi.-allylpalladium complexes. J. Am. Chem. Soc. 100, 3416-3426 (1978).

26. Pattillo, C. C., Strambeanu, I. I., Calleja, P., Vermeulen, N. A., Mizuno, T. \& White, M. C. Aerobic linear allylic C-H amination: Overcoming benzoquinone inhibition. J. Am. Chem. Soc. 138, 1265-1272 (2016).

27. Qi, X.-X., Chen, P.-H. \& Liu, G.-S. Catalytic oxidative trifluoromethoxylation of allylic C-H bonds using a palladium catalyst. Angew. Chem. Int. Ed. 56, 9517-9521 (2017).

28. Petranyi, G., Ryder, N. S. \& Stutz, A. Allylamine derivatives: new class of synthetic antifungal agents inhibiting fungal squalene epoxidase. Science 224, 1239-1241 (1984).

29. Ye, Z.-S., Brust, T. F., Watts, V. J. \& Dai, M.-J. Palladium-catalyzed regio- and stereoselective Y-arylation of tertiary allylic amines: Identification of potent adenylyl cyclase inhibitors. Org. Lett. 17, 892-895 (2015).

30. Kitahata, N. et al. A 9-cis-epoxycarotenoid dioxygenase inhibitor for use in the elucidation of abscisic acid action mechanisms Bioorg. Med. Chem. 14, 5555-5561 (2006).

31. Hanley, P. S. \& Hartwig, J. F. Intermolecular migratory insertion of unactivated olefins into palladiumnitrogen bonds. steric and electronic effects on the rate of migratory insertion. J. Am. Chem. Soc. 133, 15661-15673 (2011).

\section{Figures}
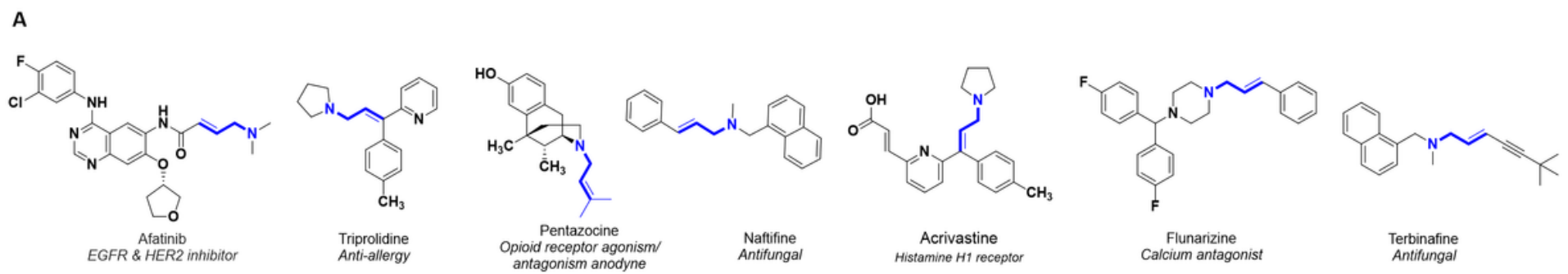

B Nitrogen-based nucleophiles for oxiadative amination

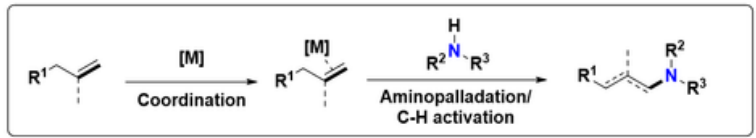

$R^{2}=E W G, R^{3}=E W G / A|k y|$

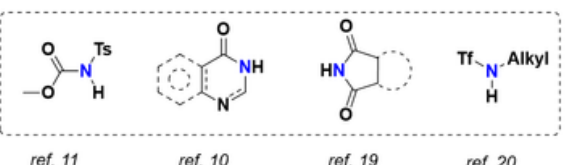

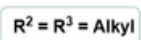

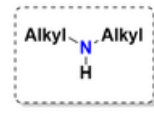

No example
C

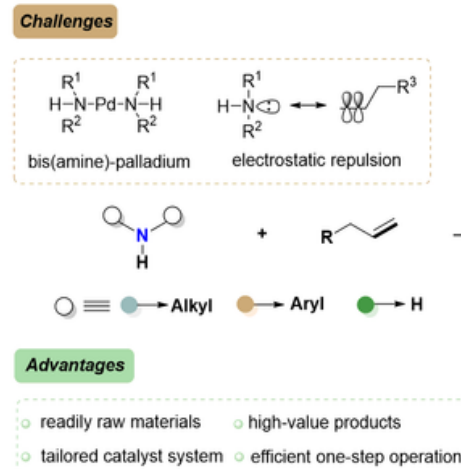

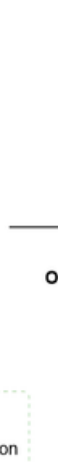


Figure 1

A, Examples highlighting the significance of allylic amines in the pharmaceutical industry. B, Nitrogenbased nucleophiles for oxidative ami-nation reactions. C, Transition-metal-catalyzed oxidative amination of olefins with aliphatic and aromatic amines: challenges and advantages.

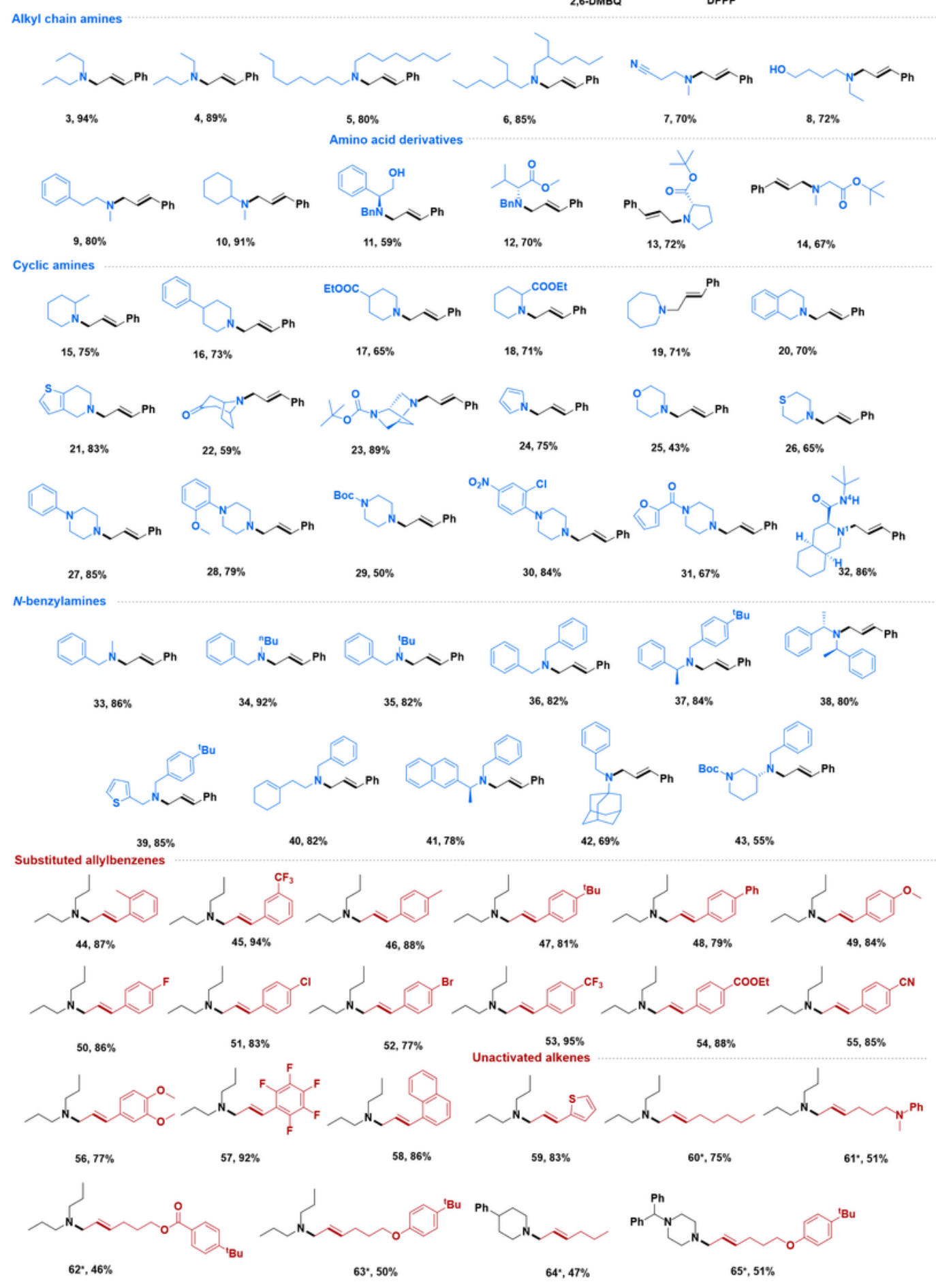

Figure 2 
Scope of aliphatic amines and olefines in the oxidative amination reaction. Reactions conditions: amine (0.2 mmol), olefine (0.24 mmol), Pd(OAc)2 (5 mol \%), DPPP (10 mol \%), 2,6-DMBQ (0.3 mmol), toluene (2 $\mathrm{mL}), 70{ }^{\circ} \mathrm{C}, 24 \mathrm{~h}$ under $\mathrm{N} 2$ atmosphere. Isolated yields are giv-en. ${ }^{*} \mathrm{Pd}(\mathrm{dba}) 2(5 \mathrm{~mol} \%)$, olefin (0.6 mmol), MTBE (2 mL). DPPP = 1,2-bis(diphenylphosphino)propane; 2,6-DMBQ = 2,6-dimethyl-1,4-benzoquinone, MTBE = methyl tert-butyl ether.

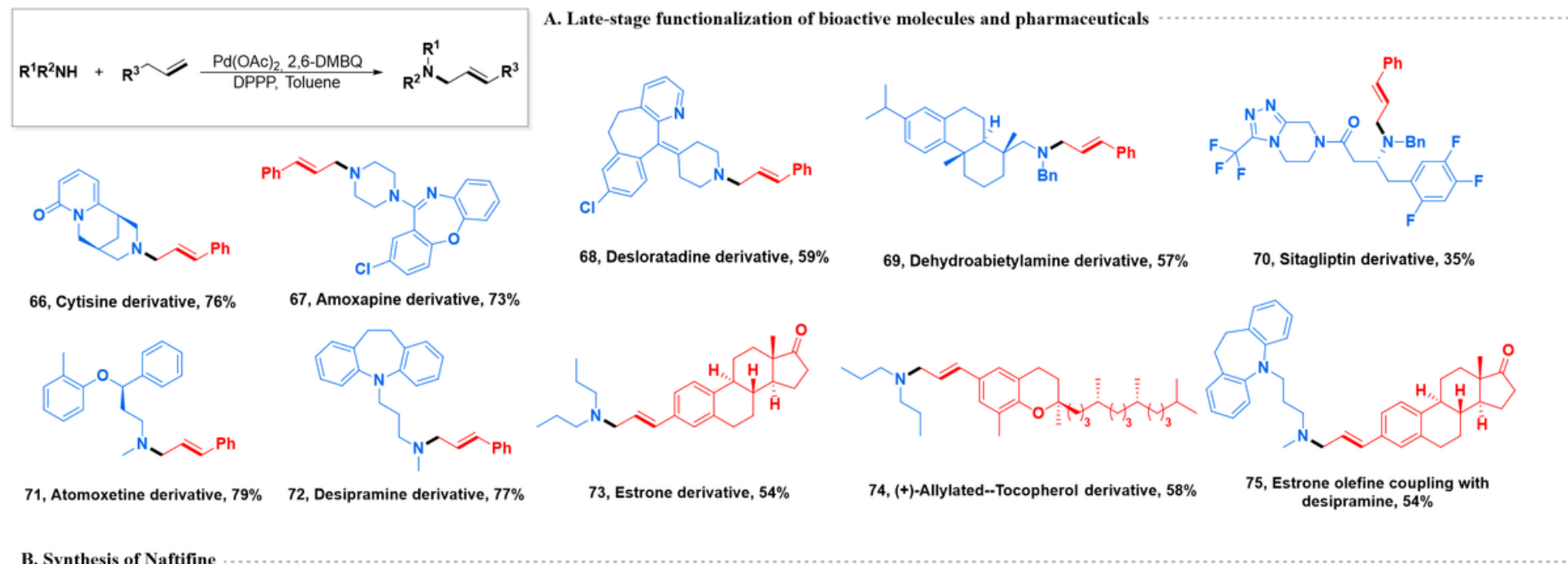

B. Synthesis of Naftifine

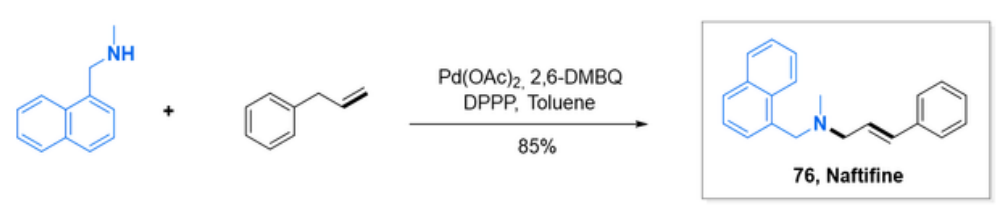

C. Synthesis of Cinnarizine and Flunarizine

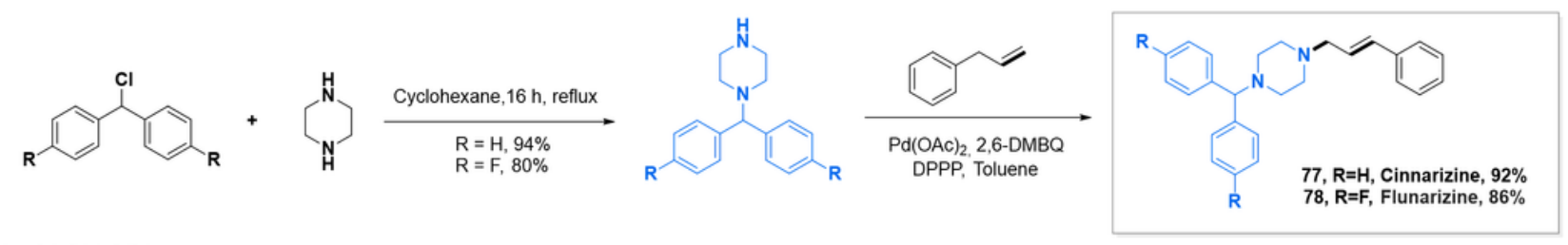

D. Synthesis of $\mathrm{AC} 1$ inhibitor

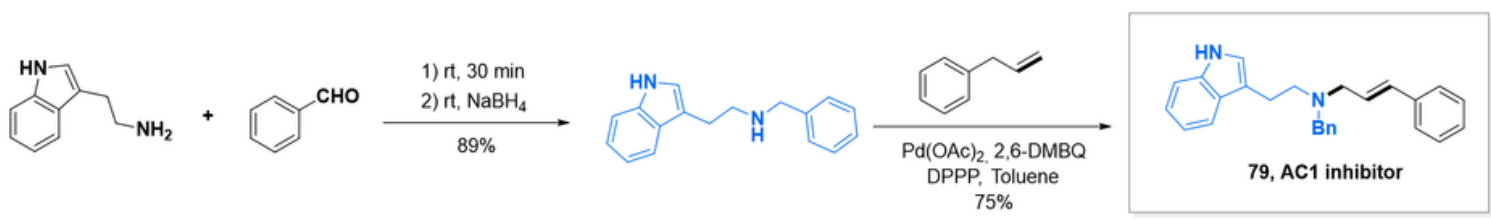

E. Synthesis of Abamine SG

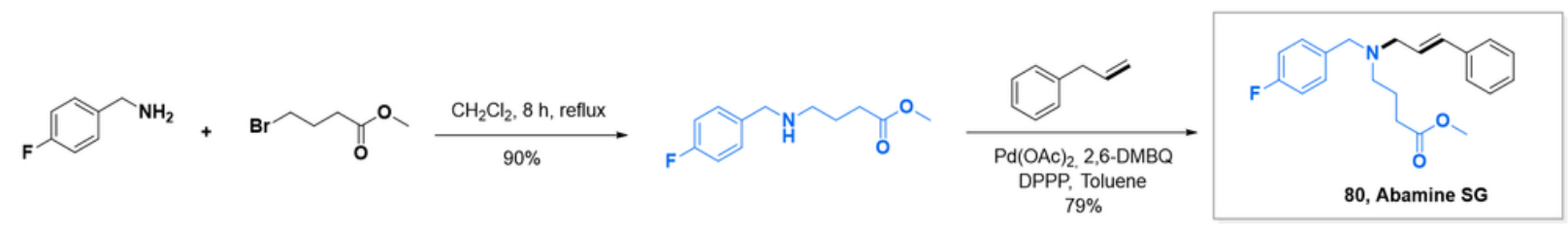

Figure 3

A, Late-stage functionalization of bioactive molecules and pharmaceuticals. Reactions conditions: amine (0.2 mmol), olefin (0.24 mmol), Pd(OAc)2 (5 mol \%), DPPP (10 mol \%), 2,6-DMBQ (0.3 mmol), toluene (2 $\mathrm{mL}), 70{ }^{\circ} \mathrm{C}, 24 \mathrm{~h}$ under $\mathrm{N} 2$ atmosphere. Isolated yields are given. $\mathrm{DPPP}=1,2-$ 
bis(diphenylphosphino)propane; 2,6-DMBQ = 2,6dimethyl-1,4-benzoquinone. B-E, Synthesis of chemical drugs.

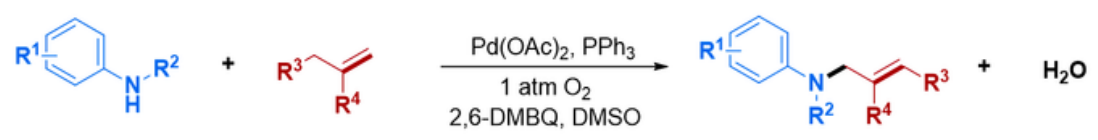

Intermolecular amination

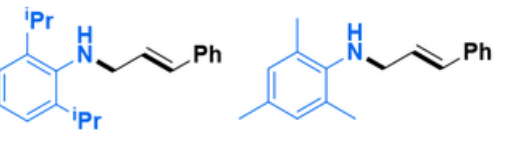

$90,63 \%$<smiles>Fc1ccc(NC/C=C/c2ccccc2)cc1Cl</smiles>

$91,50 \%$

$92,81 \%$

$93,72 \%$

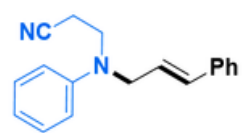

$98,73 \%$

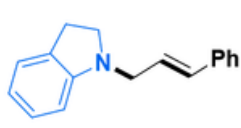

$99,81 \%$

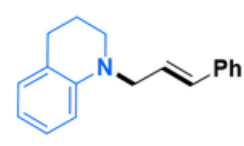

$100,83 \%$

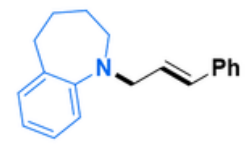

$101,80 \%$

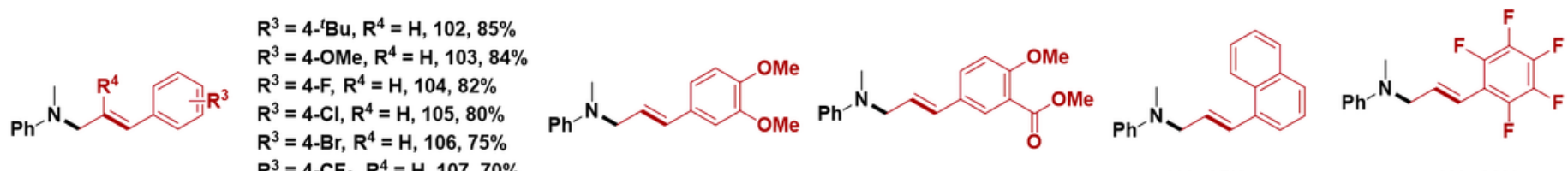

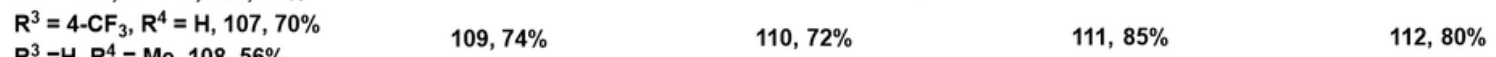<smiles>CCCCC/C=C/CN(C)c1ccccc1</smiles>

$113,75 \%$

$114,83 \%$

$115,52 \%^{\dagger}$

$116,58 \%^{\dagger}$

$117,30 \%^{\dagger}$

Intramolecular amination

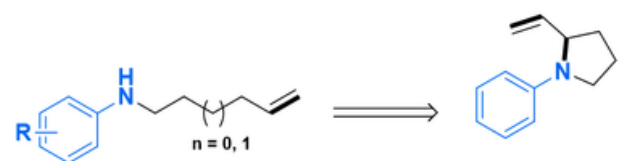

118

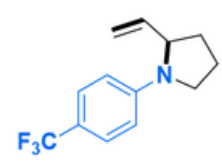

$124,78 \%$

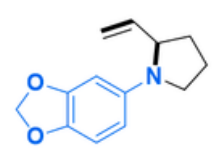

$125,98 \%$

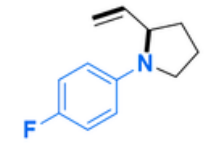

$120,88 \%$

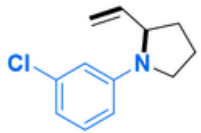

$121,94 \%$<smiles>C=CC1CCCN1c1ccc(Br)cc1</smiles>

$122,82 \%$

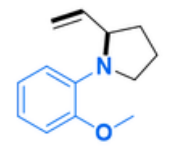

$123,90 \%$

\section{Figure 4}

Scope of aromatic amines and olefines in the oxidative amination reaction. Reactions conditions: amine (0.2 mmol), olefine (0.4 mmol), Pd(OAc)2 (10 mol \%), PPh3 (20 mol \%), 2,6-DMBQ (20 mol \%), DMSO (2 $\mathrm{mL}), 55^{\circ} \mathrm{C}, 24 \mathrm{~h}$ in the air. Isolated yields are given. $+(\mathrm{DMSO}: \mathrm{DMA}=1: 1) \neq \mathrm{Pd}(\mathrm{dba}) 2(5 \mathrm{~mol} \%), \mathrm{DPPP}(10$ $\mathrm{mol} \%), 2,6-\mathrm{DMBQ}$ (1.5 equiv), $118(0.2 \mathrm{mmol}), \operatorname{MTBE}(2 \mathrm{~mL}), 60 \mathrm{oC}, 24 \mathrm{~h}$ under $\mathrm{N} 2$ atmosphere. DPPP = 1,2-bis(diphenylphosphino)propane; 2,6-DMBQ = 2,6-dimethyl-1,4-benzoquinone, MTBE = methyl tert-butyl ether. 

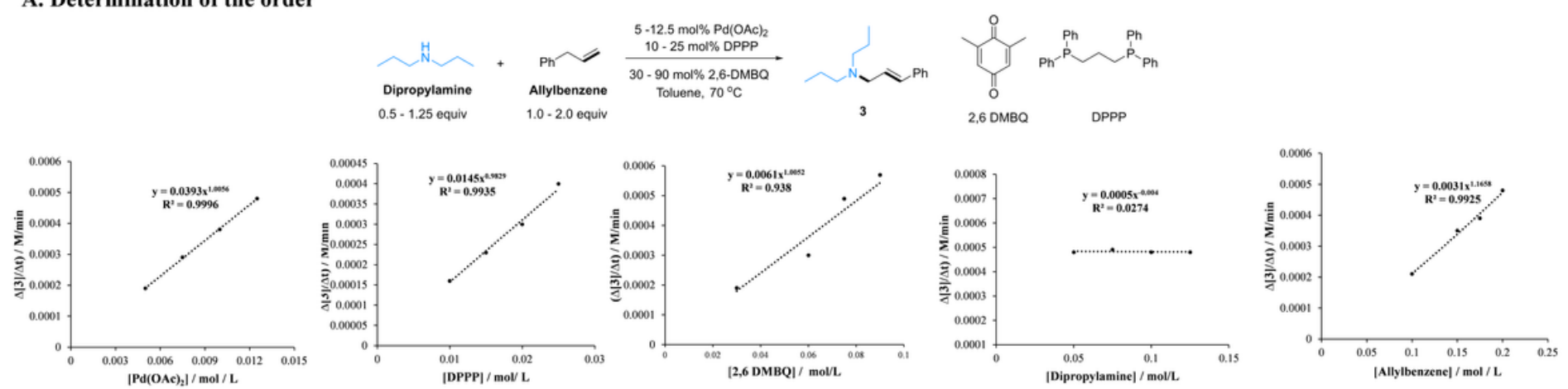

B. Kinetic isotopic effect experiments
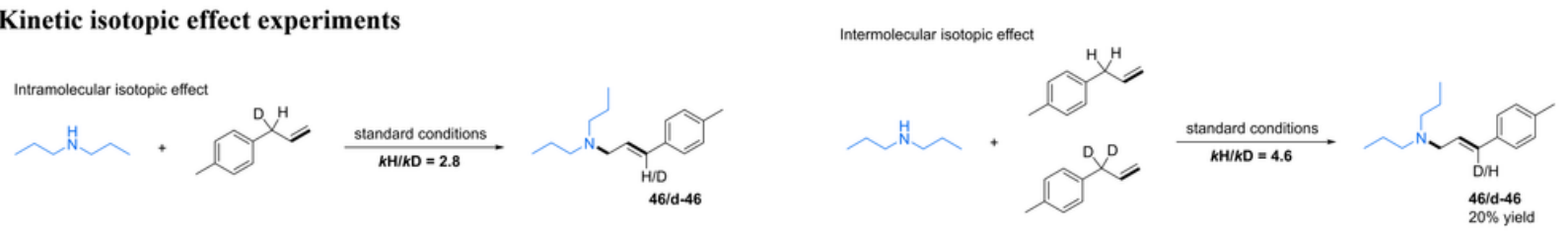

C. Hammett experiments

\begin{tabular}{c|c|c}
$\mathrm{R}$ & $\sigma_{\mathrm{R}}$ & $\log _{10}\left(\mathrm{k}_{\mathrm{R}} / \mathrm{k}_{\mathrm{H}}\right)$ \\
\hline $\mathrm{H}$ & 0.00 & 0.0000 \\
$4-\mathrm{Me}$ & -0.17 & -0.0604 \\
$4-\mathrm{OMe}$ & -0.27 & -0.1004 \\
$4-\mathrm{Cl}$ & 0.23 & 0.0188 \\
$4-\mathrm{CF}_{3}$ & 0.54 & 0.3718
\end{tabular}

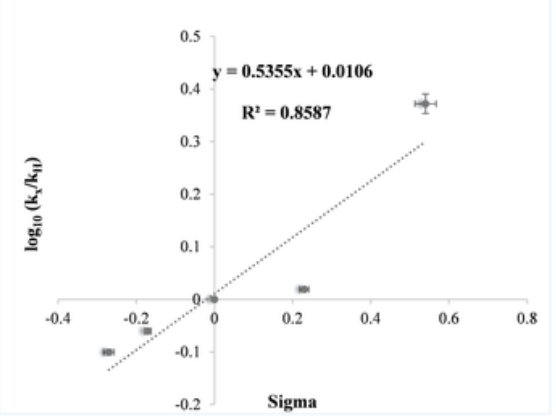

D. Proposed mechanism

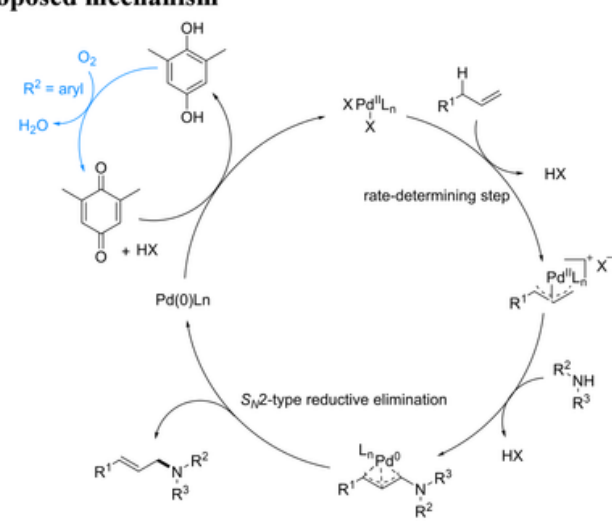

\section{Figure 5}

A, Determination of the order for the oxidative amination. B, Deuterium kinetic isotopic effect (KIE) studies. C, A Hammett investigation for the electronic effect on substituents appended to the olefins. D, Proposed mechanism.

\section{Supplementary Files}

This is a list of supplementary files associated with this preprint. Click to download.

- NatureChemistryTOC.pdf

- NatureChemistrySI.pdf

- compound67.cif 